S. BUSHUYEV, Dr.Sc., professor, Kiev National University of Construction and Architecture, Kiev;

T. MINAYEVA, PhD student, University of Government of Russian Federation, Moscow

\title{
MANAGEMENT OF DEVELOPMENT PROGRAM FOR INTERNATIONAL COMPANIES' IN TURBULENCE ENVIRONMENT
}

Theoretical aspects and elements of the methodology for modeling business environment international company based on the value-added chain (value) for interested parties should take into account the socio-economic, infrastructural and market components. We investigate the construction of such a business strategy of the international company that provides commercial, economic, fiscal and social efficiency of its activities on the basis of the selection of activities that bring the highest added value.

Ключові слова: value, value-added chain, an international company, simulation, strategy

Introduction. Research of business activity processes in the main level of the national economy - organizations, enterprises - is crucial. Precisely this level of management, its ability to achieve and maintain a sustainable and innovative business development is determinative for the regulation of stabilization of the main segments of economic space: regional, national, international, global. Internationalization of labor and production division technologies significantly changed organizational and management structure of business entities. Outpacing, compared to the real sector of the economy, growth of large financial corporations is accompanied by the formation of new possibilities of financial tools regulation for capital allocation between competing ways of resource usage in the sectoral breakdown. Spreading of global production networks, formation of trade turnover just as between affiliated partners within separate large international companies (IC), so and beyond the individual transnational corporations (TNCs), along with the activities of national small, medium and large businesses with a closed production cycle of goods, rendering services, are changing the existing notion about the content of trade. As opposed to traditional barter operations, interosculation processes of production-technical links and interjacent results, assumed in the added-value chains creation within the framework of the world economy, are forming international direct links between the major industrial firms involved in the final product creation.

Within frequent cyclical downturns in the economy, requiring innovative management decisions particularly was showed in relief relative character of socioeconomic systems (SES) viability. Acceleration of problems of social development in the XXI century was accompanied by updating many components of regulatory

(C) S. Bushuyev, T. Minayeva, 2015

ISSN 2311-4738. Вісник НТУ «ХПI»». 2015. № 1 (1110) 
mechanisms of business sustainability with significant differences compared to the previously known standards. First of all, it has become easier to conduct evaluations of the development of unforeseen situations in the technical mode there are many models for the calculation of financial performance generated. On the other hand, due to the increasing variability and uncertainty of future decisions, macroeconomic forecasting is currently complicated. Disorder economic life became normal, so antirecession management and governance internally transformed into various built-in mechanisms of management.

Analysis of recent achievements along the problem. Transition problems of national economies on way of innovative development, i.e. from raw material economy to a "knowledge economy", accompanied by substantial changes in the structure of resources instead of natural, taking into account the functional load, the products of intellectual labor become the same, with practical application. Is meant that even in the presence of significant amounts of empirical intellectual capital, it's necessary to convert scientific achievements into effective innovations. The concept of the information society also contains a significant resource that is associated with a certain system of information flows hubs - so-called "symbolic capital".

Excretion of unsolved tasks. If in the $\mathrm{XX}$ century the basic functional content of antirecession management was determined primarily by limited resources, by need for swift decision-making, by negative indicators of the organization activities, and then in the XXI century fundamentally new features of the stability regulation have appeared, associated with the restructuring of the institutional environment. Becoming the main achievement of stability, sustainability, this must be confirmed by the fact that in any scenario, the probability of a sharp drop in economic activity indicators will be minimal. Such approaches should minimize the probability of crisis or as a result of excessive "overheating" of the economic system, or as a result of stagnation, recession. In this context it should be noted that the recovery of the economies of developed and developing countries occurs at different rates.

Formation of article purposes and task statement. While developing countries have already reached the pre-crisis development indicators, growth in developed countries remains low, as evidenced by the economic indicators that are below of potential [3]. The reasons for such a situation in the euro area have become inefficient as monetary, fiscal policy, and the lack of flexibility in the labor market. Such external and internal risk factors are also present in the IC activity.

Formation of stable enterprise management mechanisms now possible only if a number of important components exists: adequate regulation - external (supranational, state), and internal. Antirecession management in the enterprise in whole should be reflected in an appropriate strategy based on the use of integrative 
synergy effect of effective management at all levels. For this purpose this article explores the properties of the activities groups of international companies, conducted selection of criteria for determining the rational functional purpose of activity in the context of business value-added chains. In addition, the methodological substantiation of functional development evaluation of alternative variety of international companies activities done to consider many factors and its complex influence on company's development.

Modeling of international company activity. Stabilization measures related to the rational use of traditional, peculiar to the end of the last century, main resource factors (natural, physical, human, financial) continues to play a large role in the economy. At the same time, the general financialization is accompanied by new risks of depressive phenomena. Inadequacy of monetary instruments and the formation of financial "bubbles" significantly lengthened chain risks for subjects of savings and investors, and for most of the financial sector.

Modelings of IC business environment based on added- value chain (value) creations for stakeholders should take into account the socio-economic, infrastructural and market components. The aim of our research is to build a business strategy of the international company that provides commercial, economic, fiscal and social efficiency of its activities on the basis of the selection of activities that bring the highest added value.

We introduce the following definition.

Definition 1. An Activity of international company $P$ in a given business environment $C$ is a collection of elements of activity $\{P 1, \ldots P J\}$, which described by value-added chains $Z$ with groups of features $Z=\left(Z_{1}, . . Z_{m}, . ., Z_{M}\right)$, where $M$ - number of considered groups of features, that affect on decision making about appropriateness of this activity type of international organizations .

Groups of particular features $Z_{m}$ of Activity $P_{j}$ have different functional meaning, dimensionality, ranges of possible values.

Definition 2. An Element of added-value $A_{i} \in A=\left(A_{1}, A_{2}, \ldots, A_{i}, \ldots, A_{N}\right)$, where $A$ - is a multitude of alternative variance of added-value creation as a result of international company activity, which is connected to variance of realization $P$.

Multitude A consists number of business activities.

Definition 3. By object of International company activity we will mean multitude element $M_{\text {object }}$ :

$$
M_{\text {object }}=M_{\text {object }}^{1} \cup M_{\text {object }}^{2} \cup M_{\text {object }}^{3} ; \quad M_{\text {object }}^{i} \cap M_{\text {object }}^{j}=\varnothing, i \neq j,
$$

where: $M_{\text {object }}^{1}-$ object of activity of first type; $M_{\text {object }}^{2}-$ object of activity of second type;

$M_{\text {object }}^{3}-$ object of activity of third type. 
Multitudes $M_{\text {object }}^{i}$ have a look:

$$
M_{\text {object }}^{i}=\left\{m_{1}^{i}, m_{2}^{i}, . ., m_{N_{i}}^{i}\right\}, i=\overline{1,3},
$$

where: $m_{n}^{i}, n=1,2, . ., N_{i}$ - elements of multitude $M_{\text {object }}^{i}$.

Object of activity (business) of international company $m_{n}^{i} \in M_{\text {object }}^{i}$ is defined by multitude of particular attitude $P_{n}^{i}=\left\{p_{n 1}^{i}, . . p_{n k}^{i}\right\}$. We distinguish next multitudes of attitudes: $P_{n 1}^{i}$ legal, $P_{n 2}^{i}$ country, $P_{n 3}^{i}$ managerial, $P_{n 4}^{i}$ functional attitudes of business object of international company $m_{n}^{i}$.

$$
P_{n}^{i}=P_{n 1}^{i} \cup P_{n 2}^{i} \cup P_{n 3}^{i} \cup P_{n 4}^{i}
$$

By multitude of particular attitudes $P_{n 3}^{i}$ of object $m_{n}^{i}$ is defines its assignation, which defines main function, which is running by business object of international company in conditions of its interaction with environment, the need to implementation of which is to create $m_{n}^{i}$.

Differentiation of functions is important, because objects of different functional attitudes interact with business environment and its elements by different ways.

In Table 1 represented Analysis of strategy characteristics of international company depending of its preferenses.

Table 1 - Strategies of Business realization by International company

\begin{tabular}{|c|c|c|}
\hline Strategy & Cost-oriented & Profit-oriented \\
\hline Profit type & From business sale & From business utilization \\
\hline Decision making criteria & Liquidity & Profitability \\
\hline Project rate & $\begin{array}{c}\text { Sale cost of business } \rightarrow \\
\text { max }\end{array}$ & $\begin{array}{c}\text { Profit from business utilization in } \\
\text { Value-added chain } \rightarrow \text { max }\end{array}$ \\
\hline
\end{tabular}

Let us consider the method of determining the optimal functionality of the elements of the international company $P$ activities, which allows considering features for performance analysis of added-value chain efficiency of international company business with different investment strategies. The method consists of the following steps:

1. Determination of multitude elements $\left\{P_{1}, \ldots P_{J}\right\}$ within business boundaries of international company.

2. Excretion of Next element of Analysis $P_{j}$.

3. Monitoring, analysis and forecasting changes in indicators of added value chains forming for $P j$. 
4. If obtained forecast values have a positive trend, go to step 5, otherwise go to step 1 .

5. Conducting research of international company activities during addedvalue chains $P j$ creation, including the level of development of the business infrastructure.

6. If the area $P_{j}$ is characterized by well-developed business infrastructure, go to step 7, otherwise go to step 1 .

7. Monitoring, analysis and forecasting changes in indicators of added value chains forming for $P j$.

For each alternative $A_{i}, i=1, . . N$ :

7.1 Determination of values of actual $D_{i}$ and perspective $D_{i}^{T}$ demand, actual $S_{i}$ and perspective $S_{i}^{T}$ offer on market segment i - of international company activity.

7.2. If $D_{i}^{T} \geq S_{i}^{T}$, go to 7.4, otherwise go to 7.1.

7.3. Determination of price parameters: market price parameter in case of business sale $C_{i}, C_{i}^{T}$, market price parameter in case of business rent $R_{i}, R_{i}^{T}$.

7.4. Determination of profitability parameters (indexes): $I_{i}=\left(C_{i}^{T}-C_{\text {invest }}\right) / C_{\text {invest }}-$ profitability index in case of business sale, $K_{i}=\left(12 * R_{i}^{T}\right) / C_{i}^{T}-$ profitability index in case of business rent (on franchising base or other schemes), where $C_{\text {invest }}$ - market parameter of investment costs for object creation of functional purpose i-, generated during the monitoring.

$7^{\text {th }}$ step. If international organization strategy oriented to cost minimization, than $A^{\text {opt }}=A_{i}$, for each, $I_{i}=I_{\max }$.

If international organization strategy oriented to profit maximization in addedvalue chains of business utilization, than $A^{\text {opt }}=A_{i}$, for each $K_{i}=K_{\max }$.

On basis of priori information dynamic models of offer $S$ and demand $D$ functions for business with different functional purposes are developed.

Amount of offer $S$ on business market of international companies in moment of time $t$ looks:

$$
S=S(t)=S(t-\tau)+S^{+}(\tau)-S^{-}(\tau),
$$

where $S(t-\tau)$ - market offer in a given period of retrospective;

$S^{+}(\tau)$ - amounts of offer, entered into circulation in the period, as a result of business development; 
$S^{-}(\tau)$ - amounts of offer, derived from turnover during the period, as a result of business reprofiling.

To determine the price indicators for use on the 7th stage non-price factors were identified and the model of demand for international company business for all elements of Ai multitude is obtained.

In particular, demand for business objects must be differentiated depending on the groups. Then the factor model of demand evaluation for a separate group of business is as follows:

$$
D_{2}(p, Z, C, \lambda)=\sum_{i=1}^{n} \frac{\alpha_{i}(p \Psi+C)}{O_{i}},
$$

where $D_{2}$ - demand on this business market, $n$ - objects or business groups of objects quantity;

$\mathrm{O}_{i}$ - required sales amount for business object, $i-$ in monetary terms;

$\alpha_{i}$-share of the buyers costs of international company business on the type $\mathrm{i}$ - of business object in the overall cost structure;

$p$ - average income of buyers, $\Psi$ - forecast total employment of buyers;

$C$ - Other cash income of buyers.

Customer quantity forecast:

$$
K=K_{F} \frac{\Psi}{\Psi_{F}},
$$

where $K_{F}$ и $\Psi_{F}$ - quantity of buyers and average employment in the last accounting period.

Multicriteria optimization task of choosing the option of functional assignment of business object during the international company development project realization described below.

Quantitative expression of a group of attitude $Z_{m}$ of business objects $P_{j}$ is vector criteria $K_{m}, m=\overline{1, M} . K_{m}=\left\{k_{m}^{1}, k_{m}^{2}, \ldots, k_{m}^{g_{m}}\right\}$, where particular criteria $k_{m}^{r}$, $r=\overline{1, g_{m}}$ - quantity evaluation of attitude $Z_{m}^{r}$. Let's define $L=\sum_{m=1}^{M} g_{m}$. Then criteria multitude $K$ relative to the business elements $P_{j}$ could be represented as $\left\{k_{1}^{j}, k_{2}^{j}, \ldots, k_{L}^{j}\right\}$.

Then the task of choosing the option of functional development of international company business $P_{j}, j=\overline{1, J}$, looks:

To find:

$$
A_{o p t}^{j}=\underset{A_{i} \in \mathrm{A}}{\arg \max } \phi\left(W_{i}, F_{j}\right)
$$


where $\phi\left(W_{i}, F_{j}\right)$ - additive function of business added- value,

$$
W_{i}=\left(w_{1}^{i}, w_{2}^{i}, \ldots, w_{l}^{i}, \ldots, w_{L}^{i}\right)
$$

Value evaluation of particular criteria $\left\{k_{1}^{j}, k_{2}^{j}, \ldots, k_{L}^{j}\right\}$ when chhosing alternative $A_{i}$;

$$
F_{j}=\left(f_{1}^{j}, f_{2}^{j}, \ldots, f_{l}^{j}, \ldots, f_{L}^{j}\right), j=\overline{1, J}
$$

monic evaluation vector of territorial element $P_{j}$ particular attitudes.

Task (9)-(11) is a multicriteria task of discrete optimization.

Proposed method for solving the problem consists of the following steps:

Determination of particular criteria value в $k_{\mathrm{l}}, l=\overline{1, L}$ for choosing an alternative $A_{i}$ with usage of score method of expert evaluation, $i=\overline{1, N}$.

Expert evaluation $b_{i l}$ of criteria $k_{1}$ value for choosing an alternative $A_{i}$ consists to range of integers $[1 ; 10]$ Definition of criteria group value $K_{m}, m=\overline{1, M}$.

Evaluations $\lambda_{i m}^{\prime}, \lambda_{i m}$ of accordance of m-group criteria to maximum $b_{i-\max }^{m}=\max _{l \in\left[r+1, r+g_{m}\right]} b_{i l}, \quad r=\sum_{k=1}^{m-1} g_{k}$, relative to alternative $A_{i} a$ are determinate by the formula:

$$
\lambda_{i m}^{\prime}=\frac{\sum_{k=r}^{r+g_{m}} b_{i k}}{g_{m} \cdot b_{i_{-} \max }^{m}}
$$

Determination of $\lambda_{i m}=\frac{\lambda_{i m}^{\prime}}{\sum_{m=1}^{M} \lambda_{i m}^{\prime}}$ value $\theta_{i m}^{r}$ of particular criteria $k_{i m}^{r}$ in each $m$ - group relative to alternative $A_{i}$. Evaluations $\theta_{i r}^{\prime}$ of score accordance $b_{i r}$ to maximum:

$$
\theta_{i m}^{r}=\frac{b_{i m}^{r}}{\sum_{r=1}^{g_{m}} b_{i m}^{r}}, r=\overline{1, g_{m}}, m=1, \bar{M}
$$

As a result we have a matrix composition:

$$
\Theta=\left[\theta_{i l}\right], i=\overline{1, N}, l=\overline{1, L} .
$$


Composition of matrix $\tilde{W}$ of value evaluation of partial criteria $k_{1}$, considering weight $\lambda_{i m}$ of appropriate groups of criteria:

$$
\tilde{W}=\left[\tilde{w}_{i l}\right]=\Theta * \Lambda_{i} ;
$$

where $\Lambda_{i}-$ vector of evaluation types (12).

4. Matrix $W$ elements of monic evaluation of criteria $k_{1}$ value for alternative $A_{i}$ are determinate by the formula:

$$
w_{i l}=\frac{\tilde{w}_{i l}}{\sum_{i=1}^{N} \tilde{w}_{i l}} .
$$

5. Composition of the local utility criteria $k_{l}^{j}$ function $f_{l}^{j}$ for the international company activity element of the $P_{j}$ type

$$
f_{l}^{j}=\frac{k_{l}^{j}-\min _{j \in J} k_{l}^{j}}{\max _{j \in J} k_{l}^{j}-\min _{j \in J} k_{l}^{j}}, l=\overline{1, L} ; j=\overline{1, J} .
$$

Received evaluations $f_{l}^{j}$ for each elements of international company activity $P_{j}$ create a vector $F_{j}=\left(f_{1}^{j}, f_{2}^{j}, \ldots, f_{l}^{j}, \ldots, f_{L}^{j}\right)$.

6. Composition of added-value chain additive function $\phi\left(W_{i}, F_{j}\right)$ :

$$
\phi\left(W_{i}, F_{j}\right)=\frac{\sum_{l=1}^{L} w_{l}^{i} f_{l}^{j}}{\sum_{i=1}^{N} \sum_{l=1}^{L} w_{l}^{i} f_{l}^{j}} .
$$

Effective interaction of static and dynamic mechanisms of sustainable development of international companies with innovative antirecession management in regional, national and global systems may become one of the main reasons that allow creating new approaches to business risk management. For this purpose management practice must be based on the above:

- groups of International companies activity abilities;

- criteria system of rational functional activity purpose definition within business added-value chains context;

- evaluation method of functional development alternative variety of international company, which allows considering many factors and its complex influence on company's development. 
Conclusions. Nowadays for each level of management should be increased the impact of antirecession regulatory tools, which take into account changes in the support resource structure of economic activity. Among them is the increase in the importance of intellectual capabilities, including the commercialization of new knowledge and qualifications that characterize human capital. Backbone circumstances in antirecession management are institutional changes. On the one hand, their influence is determined by the spatial and temporal information motivators acquiring resource value, on the other - must be considered that system of information flows hubs are rapidly formed, as well as administrative resource, as a manifestation of power and influence. Impact on the institutional environment claims supranational, state, corporate antirecession regulators, which allow taking into account the degree of globalization processes of the added-value creation.

Significance of these circumstances becomes important on the new frontier of economic development of "postindustrial" or "information" society which is different from the industrial stage of development. Predominance and accelerated development of the high-end technology sector, information technologies and services area changing the value-added chain formats. Therefore, the activities of international companies will require an implementation of the new economic and organizational Management models expounded above.

Bibliography: 1. Burdiet, P. Social Space and Symbolic Power. Moscow: Nachala, 1994. Print. 2. Burdiet, P. "Forms of Capital". Economical sociology. November 2002. Vol. 3. No. 5. Print. 3. Maracha, V. Consulting as Institutional Mechanism of Development and Practical Knowledge about Organization. Philosophy of Management: Problems and Strategies [Text]. Russian Academy of science, Institute of Philosophy; Edited by. V.M. Rozin. Moscow : IFRAN, 2010. 217-240. Print. 4. Report about Trade and Development, 2011. UNCTAD/TDR/2011. № R.11.II.D.3. Web. 30 October 2014 <http://www.un.org/ru/development/surveys/docs/tdr2011.pdf.>

Received 05.12.2014

УДК 004.415.28

И. В. КОНОНЕНКО, д-р техн. наук, проф., НТУ «ХПИ»;

A. В. ХАРАЗИЙ, аспирант, НТУ «ХПИ»

\section{РАЗРАБОТКА ПРОГРАММНОГО ОБЕСПЕЧЕНИЯ ДЛЯ МНОГОКРИТЕРИАЛЬНОЙ ОПТИМИЗАЦИИ СОДЕРЖАНИЯ ПРОЕКТА С ПОМОЩЬЮ МЕТОДА УСТУПОК}

В статье описано программное обеспечение «ScopePro», созданное для решения задачи многокритериальной оптимизации содержания проекта с помощью метода уступок, а также для

(с) И.В. Кононенко, А.В. Харазий, 2015

ISSN 2311-4738. Вісник НТУ «ХПI». 2015. № 1 (1110) 